\title{
Corneal ectasia secondary to peripheral endotheliopathy in a patient with classic pars planitis
}

\author{
Lourdes Arellanes-Garcia • \\ Maricarmen Preciado-Delgadillo • \\ Everardo Hernandez-Quintela • Manuel Garza-Leon
}

Received: 12 July 2010 / Accepted: 5 October 2010 /Published online: 23 October 2010

(C) The Author(s) 2010. This article is published with open access at Springerlink.com

\begin{abstract}
Purpose To report a case of corneal ectasia secondary to pars planitis corneal endotheliopathy

Methods Clinical case description and proposed hypothesis regarding development of corneal ectasia

Results Eight-year-old male presented with $360^{\circ}$ peripheral corneal endotheliopathy and edema, granulomatous keratic precipitates, and mild iritis OD. A progressive corneal ectasia then developed. Twenty months later, OS presented similarly and anterior chamber inflammatory cells, vitreous snowballs, and retinal vasculitis were observed OU. Classic pars planitis was diagnosed

Conclusion This is the first case of endotheliopathy as the first manifestation of pars planitis and as a cause of a secondary central cornea ectasia developed
\end{abstract}

\footnotetext{
L. Arellanes-Garcia $\cdot$ M. Preciado-Delgadillo

Clinic of Inflammatory Eye Disease, Hospital "Dr. Luis Sanchez

Bulnes" Asociación para Evitar la Ceguera en México IAP,

Mexico, Mexico

L. Arellanes-Garcia

Universidad Nacional Autónoma de México,

Mexico, Mexico

E. Hernandez-Quintela

Corneal and Refractive Surgery Department,

Hospital "Dr. Luis Sanchez Bulnes" Asociación para Evitar

la Ceguera en México IAP,

Mexico, Mexico

M. Garza-Leon $(\bowtie)$

Instituto para Preservación de la Visión,

Monterrey, Nuevo Leon, Mexico

e-mail: dr.manuel.garza@gmail.com
}

Keywords Peripheral corneal endotheliopathy $\cdot$ Classic pars planitis S Secondary corneal ectasia

\section{Introduction}

Classic pars planitis (CPP) is an idiopathic intermediate uveitis characterized by a "white eye", mild anterior chamber reaction, "snowballs" in the anterior vitreous, "snowbanks" in the peripheral retina and pars plana, retinal vasculitis, and cystoid macular edema [1]. The association of a peripheral corneal endotheliopathy (PCE) and pars planitis starting in childhood has been previously described [2]. We report a CPP case in which PCE was the first clinical manifestation, and which led to secondary corneal ectasia.

\section{Case report}

On the first visit, an 8-year-old male presented because the patient's mother noticed a white reflex in the right eye for about 2 years that became more evident with time. His past medical history showed no related conditions.

On examination, his visual acuity OD was 20/200 with improvement to 20/60 with pinhole occlusion, OS 20/20. His IOP OD was $26 \mathrm{mmHg}$ and OS was $18 \mathrm{mmHg}$. The left eye was normal throughout. OD showed mild ciliary injection, mild peripheral corneal edema, a $360^{\circ}$ peripheral endothelial opacity delimitated by "mashed potato" keratic precipitates, and mild iritis (Fig. 1). No anterior or posterior synechiae were found, and the lens was clear. Vitreous examination revealed few cells and a single "snowball" in 

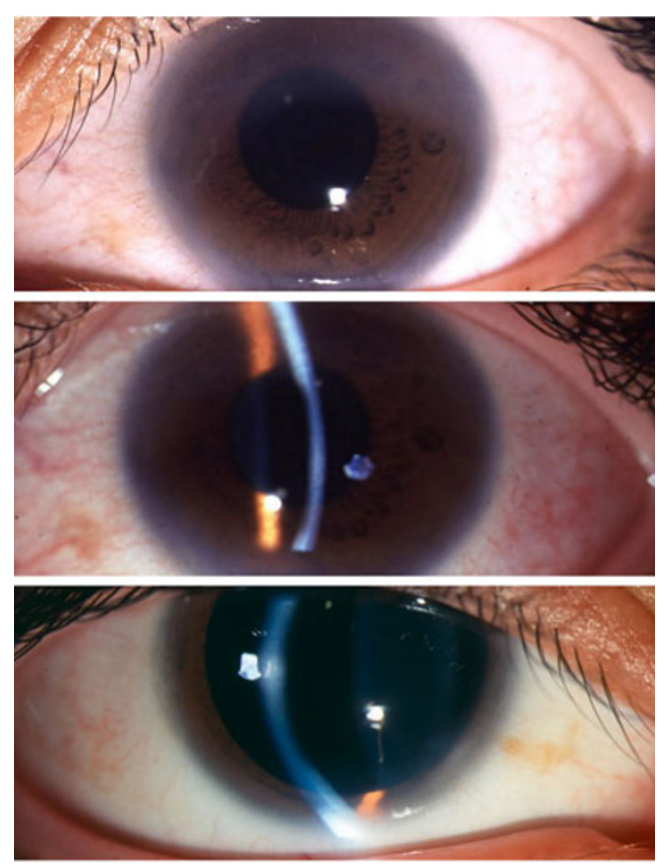

Fig. 1 Pictures showing the right eye with a peripheral corneal stromal oedema and endothelial opacity. Granulomatous KPs delineated the involved endothelial area the inferior, peripheral retina, near an area of apparent retinal vasculitis. The optic disc showed mild hyperaemia.

A diagnosis of pars planitis was suspected and fluorescein angiography (FA), PPD, VDRL, and FTA-ABS were ordered. Prednisolone acetate (Prednefrin, Allergan) $\mathrm{q} 2 \mathrm{~h}$ and Timolol 0.5\% (Imot, Laboratorios Sophia, Guadalajara, México) bid were started; the steroid was slowly tapered over a period of 1 month. All laboratory tests were either negative or normal and fluorescein angiography OU was also normal. Visual acuity improved to 20/60 OD and remained stable OS. Corneal endothelium opacity cleared almost completely and no data of intraocular inflammation was found.

One year later, the patient returned complaining of decreased VA. Examination showed VA: OD 20/400 with improvement 20/80 with pinhole occlusion, OS 20/20; IOP: $10 / 14 \mathrm{mmHg}$, with pronounced peripheral corneal stromal oedema and endothelial opacity OD. Granulomatous keratic precipitates (KPs) delineated the involved endothelial area, and some deep stromal peripheral vessels were found. A corneal conus shape was also noticed. Javal's keratometric readings were OD $40.00 / 46.25 \times 10^{\circ}$ and OS 44.00/45.00× $5^{\circ}$, he showed decreased corneal sensitivity, and there was

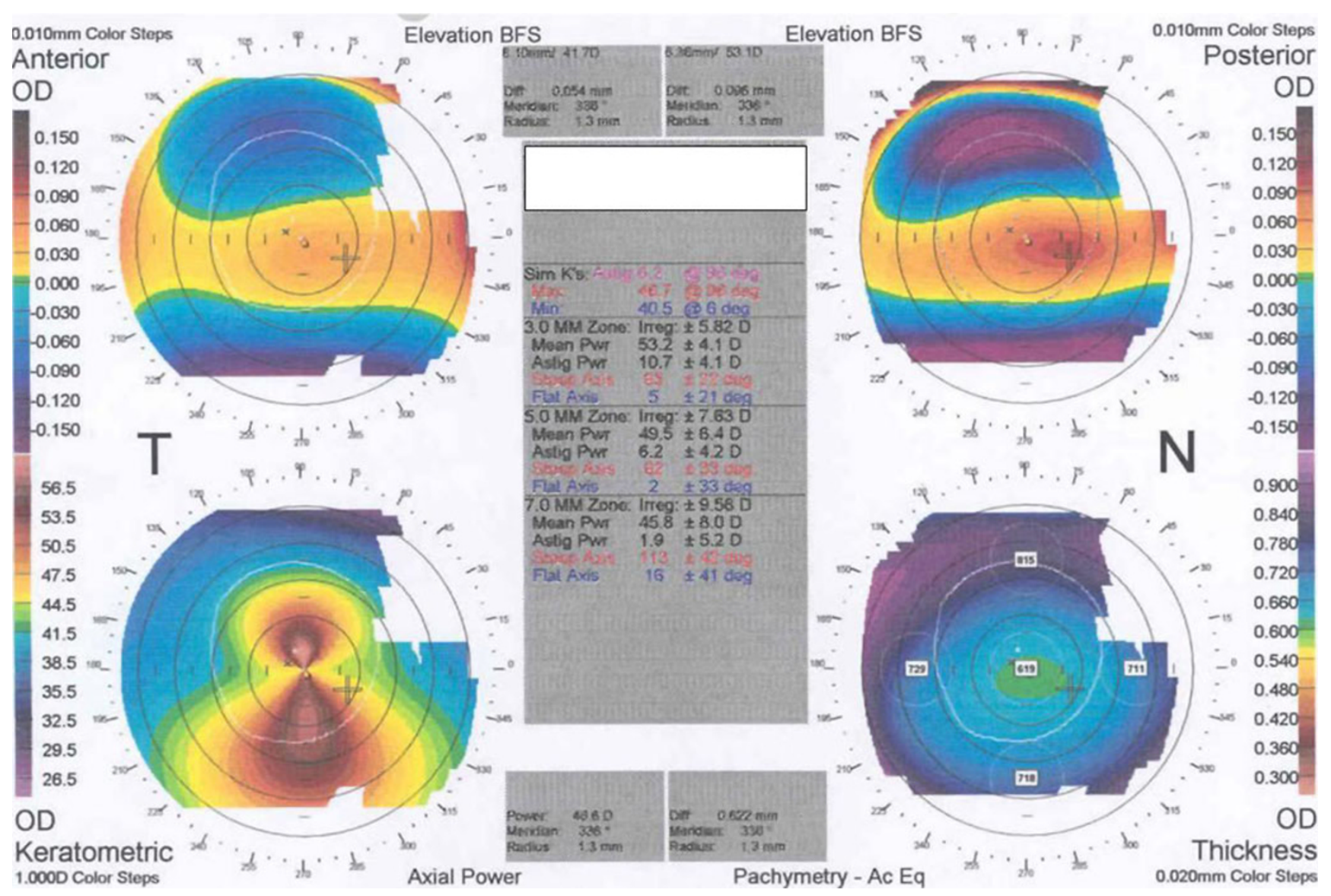

Fig. 2 Right eye Orbscan topography map. Anterior elevation map within normal values; posterior elevations map shows a central steepening of $96 \mathrm{~mm}$; and pachymetry map with increase of peripheral thickness. The keratometric map shows a asymmetrical bowtie pattern with an inferior steepest 
no anterior chamber or vitreous inflammation. Prednisolone acetate was started again and his VA improved slightly to $20 / 200$. Both the stromal and endothelial opacities diminished and so the corticosteroids were tapered during the next 2 months.

Six months later, a corneal topography (Orbscan Topography System II, Orbscan Inc., Salt Lake City, UT) was done OU. (Fig. 2 shows the findings) OD shows a with the rule astigmatism with asymmetric bowtie pattern. Central pachymetry was similar in both eyes (OD $619 \mu \mathrm{m}$, OS $617 \mu \mathrm{m})$ but the peripheral pachymetry in the OD was $900 \mu \mathrm{m}$ thicker than the OS in the superior area and $60 \mu \mathrm{m}$ in the inferior and temporal area. In the left eye (Fig. 3) a bowtie pattern with symmetric astigmatism was observed. Specular microscopy (Topcon SP-2000P noncontact specular microscope, Topcon Corp., Tokyo, Japan) of the right eye showed decreased endothelial cell density $\left(1,636 \mathrm{cell} / \mathrm{mm}^{3}\right)$ with pleomorphism and polymegatism; the left eye was normal $\left(3,141 \mathrm{cell} / \mathrm{mm}^{3}\right)$.

Three years after the initial visit, an examination showed a decreased VA OU, being OD 20/400; OS 20/30. His IOP was normal and his OD showed corneal findings very similar to those previously described, in the left eye a peripheral endothelial opacity in the inferior sector of the cornea was observed. Mild to moderate iritis and vitreous cells+ were found OU. "Snowballs" in the inferior peripheral retina and some vascular sheathing were also seen. In both eyes, FA showed hyperfluorescence of the peripheral capillary vessels, parietal hyperfluorescence of the mediumsized veins, and optic disc and perifoveal hyperfluorescence OU. A complete blood cell count, urinalysis, angiotensinconverting enzyme, and chest X-ray were carried out. All test results were either negative or normal. Based on these findings, we diagnosed a classic case of pars planitis.

\section{Discussion}

An autoimmune endotheliopathy (AE) associated with a corneal graft rejection was first described by Khodadust and Attarzadeh [3]. This condition is characterized by a peripheral endothelial opacity and stromal edema, initially located in the lower quadrants, which may progress in a circumferential pattern. Small and mutton fat KPs arranged linearly at the junction of the oedematous and nonoedematous portions of the cornea may also be present.

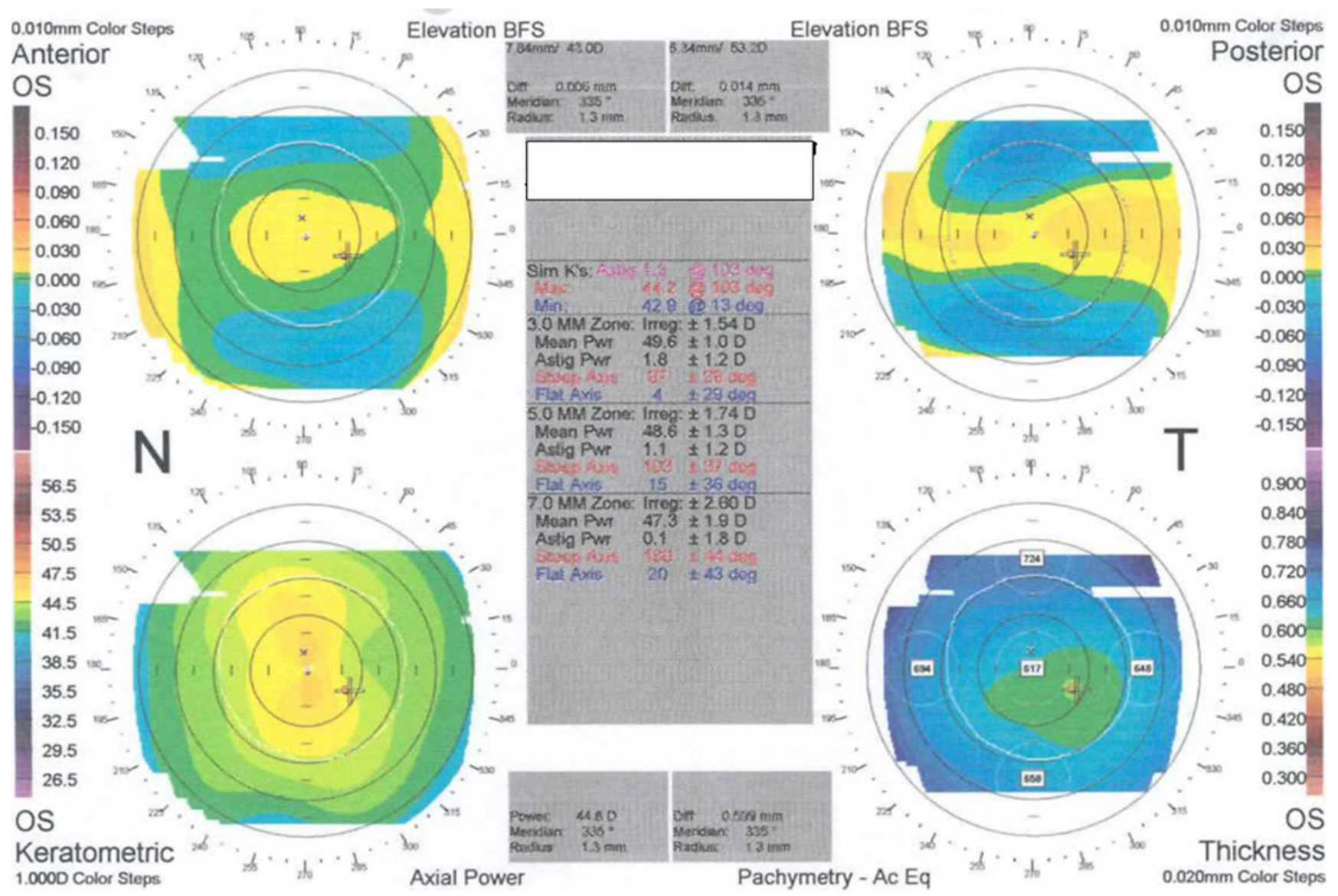

Fig. 3 Left eye Orbscan topography map. Anterior, posterior elevations, and thickness maps within normal values. The keratometric map shows a symmetrical bowtie 
These findings were first reported as isolated corneal alterations. Later, the same authors, as well as Lucchese and Tessler, described similar findings in cases of pars planitis [4] and sarcoidosis patients [5]. Autoimmune responses to the corneal endothelium, and a fibrous metaplasia of the endothelium secondary to damage caused by KP, have been suggested to explain these findings [4]. $\mathrm{AE}$ has been described in $18.8 \%$ to $25.4 \%$ of CPP patients and manifests bilaterally in $70 \%$ of cases [2].

We have hypothesized that the peripheral swelling of the cornea may induce a modification of the central curvature. These changes can be explained using the conceptual model proposed by Roberts [6], in which the lamellar collagen structure of the cornea is conceived of as a series of stacked fibrils with interlamellar spaces filled with an extracellular matrix between each layer. The collagen lamellas are in tension, due to intraocular pressure from below, and their ends are held tightly by the limbus. The amount of water at the extracellular matrix is related to the strain force at the lamellae. The biomechanical response of the cornea in the present case could be the consequence of differences in the amount of swelling throughout the cornea and alterations in the stress distribution [7]. The peripheral corneal edema may function as a belt that exerts its force centripetally, allowing the central dome of the cornea to be displaced anteriorly, thus increasing its curvature. A change in the shape of the cornea has been demonstrated to occur in the swollen eye but not in the normal hydration state. Using small-angle X-ray diffraction, Boote et al. [8] demonstrated that in physiologic conditions collagen fibrils pack around the peri-pupillary cornea (the interfibrillar space is $5 \%$ to $7 \%$ smaller than in the peripheral cornea). In the present case, this may have played a role in limiting swelling into the central cornea, explaining why the corneal edema was limited to the periphery.

\section{Conclusions}

This report is interesting because, to the best of our knowledge, this is the first report of a case in which corneal endotheliopathy is the first manifestation of pars planitis and induced the development of a secondary central cornea ectasia.

Open Access This article is distributed under the terms of the Creative Commons Attribution Noncommercial License which permits any noncommercial use, distribution, and reproduction in any medium, provided the original author(s) and source are credited.

\section{References}

1. Jabs DA, Nussenblatt RB, Rosenbaum JT, Standardization of Uveitis Nomenclature (SUN) Working Group (2005) Standardization of uveitis nomenclature for reporting clinical data. Results of the First International Workshop. Am J Ophthalmol 140(3):509-516

2. Arellanes-García L, Navarro-López L, Recillas-Gispert C (2003) Pars planitis in the Mexican mestizo population: ocular findings, treatment, and visual outcome. Ocul Immunol Inflamm 11(1):53-60

3. Khodadoust AA, Attarzadeh A (1982) Presumed autoimmune corneal endotheliopathy. Am J Ophthalmol 93(6):718-722

4. Khodadoust AA, Karnama Y, Stoessel KM, Puklin JE (1986) Pars planitis and autoimmune endotheliopathy. Am J Ophthalmol 102 (5):633-639

5. Lucchese N, Tessler H (1981) Keratitis associated with chronic iridocyclitis. Am J Ophthalmol 92(5):717-721

6. Roberts C (2000) The cornea is not a piece of plastic. J Refract Surg 16(4):407-413

7. Hennighausen H, Feldman ST, Bille JF, McCulloch AD (1998) Anterior-posterior strain variation in normally hydrated and swollen rabbit cornea. Invest Ophthalmol Vis Sci 39(2):253-262

8. Boote C, Dennis S, Newton RH, Puri H, Meek KM (2003) Collagen fibrils appear more closely packed in the prepupillary cornea: optical and biomechanical implications. Invest Ophthalmol Vis Sci 44(7):2941-2948 